\title{
Corrigendum
}

\section{Corrigendum to "Tooth Reattachment and Palatal Veneer on a Multidisciplinary Approach of Crown Fractures in Upper Central Incisors"}

\author{
Vanessa Machado, ${ }^{1}$ Ricardo Alves, ${ }^{2}$ Luísa Lopes, ${ }^{3}$ João Botelho, ${ }^{1}$ and José João Mendes ${ }^{4}$ \\ ${ }^{1}$ Egas Moniz Cooperativa de Ensino Superior, Monte da Caparica, Almada, Portugal \\ ${ }^{2}$ Department of Periodontology, Instituto Superior de Ciências da Saúde Egas Moniz, Monte da Caparica, Almada, Portugal \\ ${ }^{3}$ Department of Pediatrics, Instituto Superior de Ciências da Saúde Egas Moniz, Monte da Caparica, Almada, Portugal \\ ${ }^{4}$ Department of Dentistry, Instituto Superior de Ciências da Saúde Egas Moniz, Monte da Caparica, Almada, Portugal
}

Correspondence should be addressed to Vanessa Machado; vanessamachado558@gmail.com

Received 26 October 2017; Accepted 1 November 2017; Published 3 December 2017

Copyright (c) 2017 Vanessa Machado et al. This is an open access article distributed under the Creative Commons Attribution License, which permits unrestricted use, distribution, and reproduction in any medium, provided the original work is properly cited.

In the article titled "Tooth Reattachment and Palatal Veneer on a Multidisciplinary Approach of Crown Fractures in Upper Central Incisors" [1], there was a mistake in the first affiliation. The corrected affiliations are shown above.

\section{References}

[1] V. Machado, R. Alves, L. Lopes, J. Botelho, and J. J. Mendes, "Tooth reattachment and palatal veneer on a multidisciplinary approach of crown fractures in upper central incisors," Case Reports in Dentistry, vol. 2017, Article ID 4702635, 6 pages, 2017. 


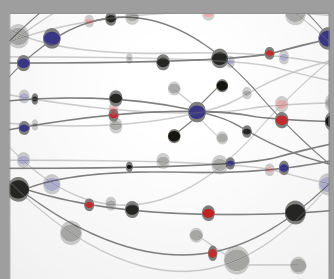

The Scientific World Journal
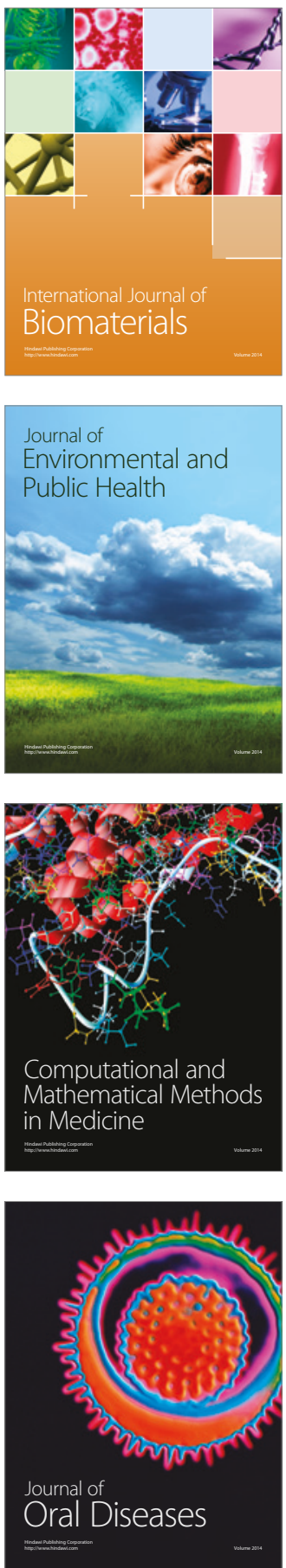
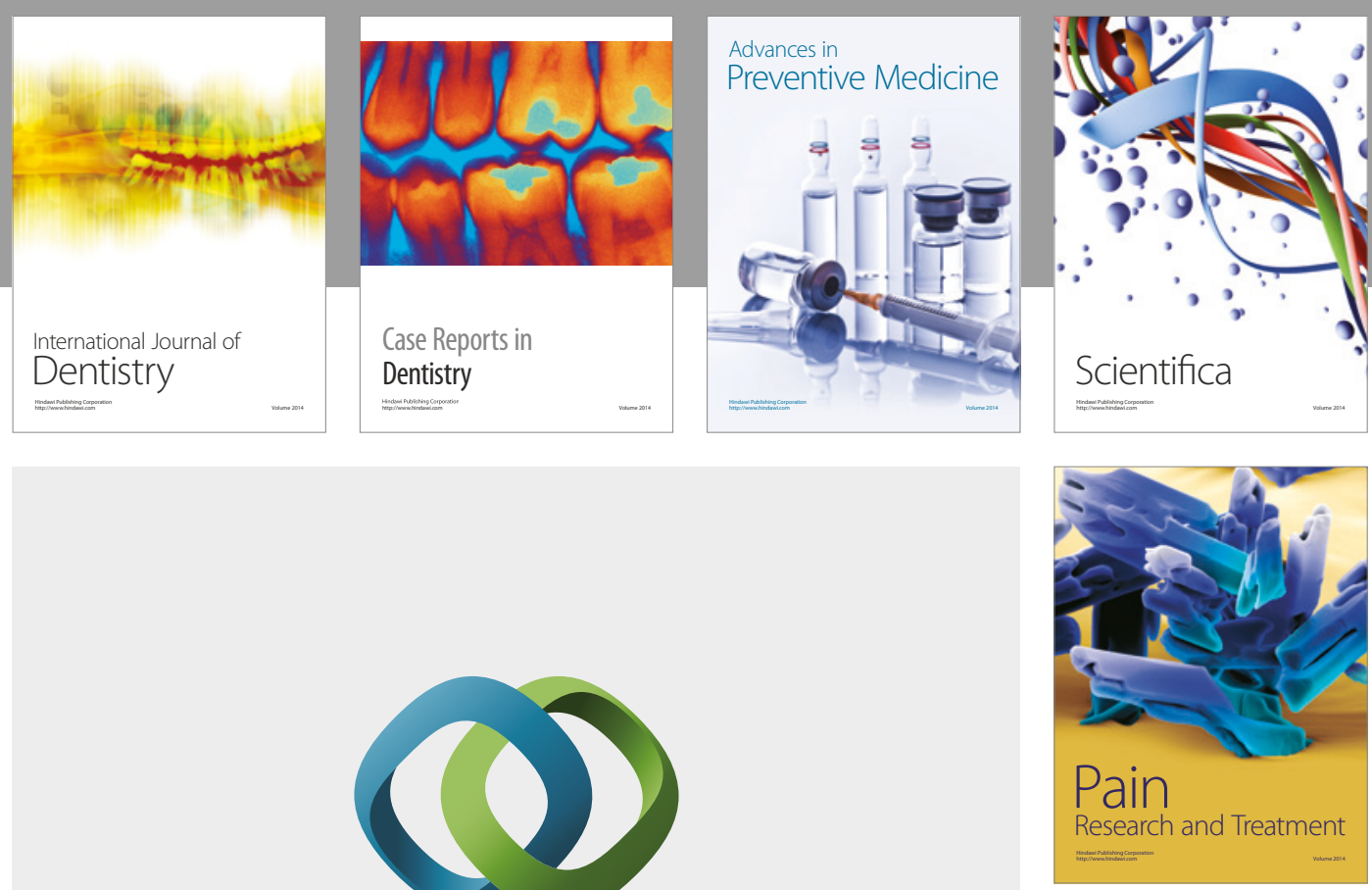

\section{Hindawi}

Submit your manuscripts at

https://www.hindawi.com
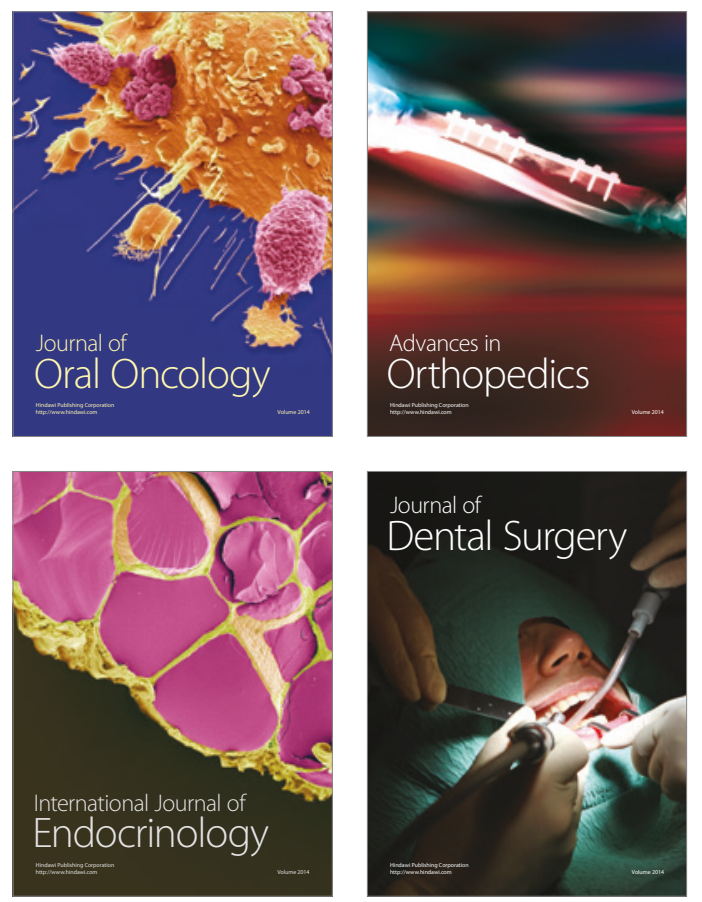
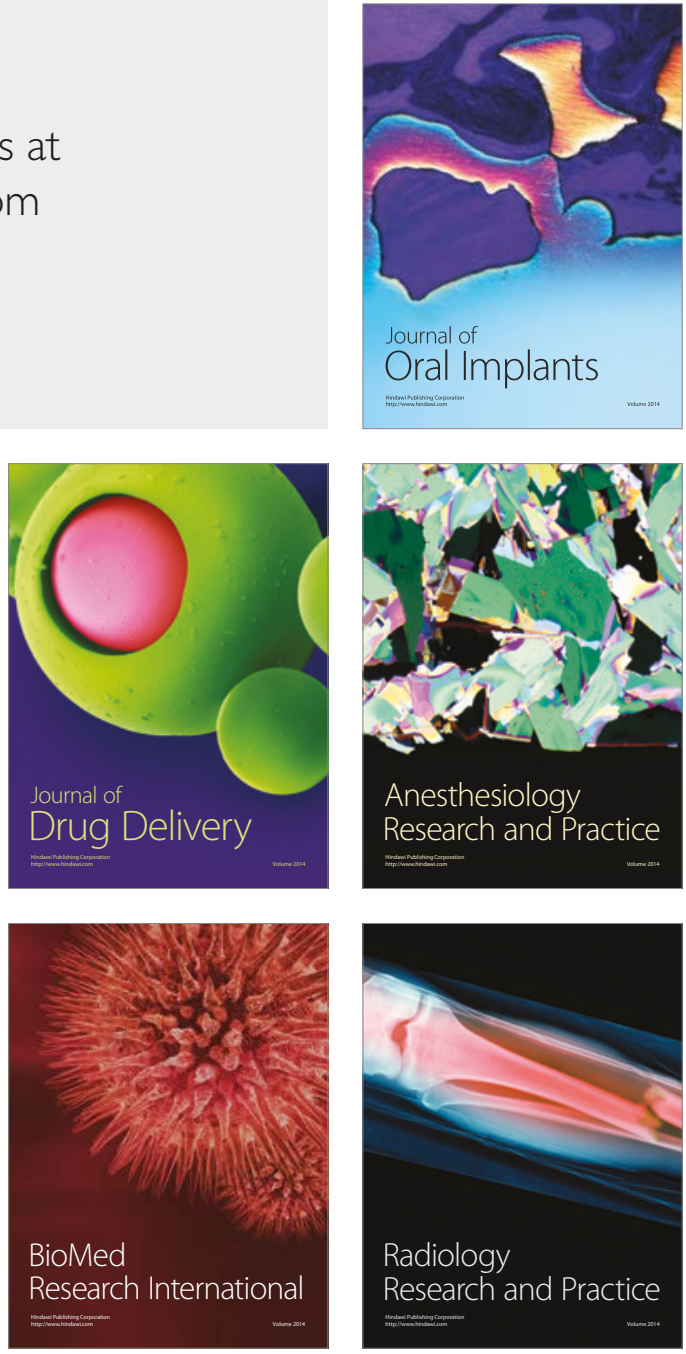